\title{
Adding Monspexy (Pubic Suspension) Step to Abdominoplasty, Does this Benefit in Management of Urinary Stress Incontinence in Females with Redundant Abdomen and Mons Pubis?
}

\author{
AYMAN M. ABDELMOFEED, M.D.*; OLA SEIF, M.D.*; MOHAMED T. YOUNES, M.D.* and \\ SHABIEB A. ABDELBAKI, M.D.** \\ The Departments of General Surgery, Plastic Surgery Unit* and Urology**, Faculty of Medicine, Benha University, Egypt
}

\begin{abstract}
Background: Abdominoplasty is a surgical procedure that removes excess skin and fat from the abdominal wall. Aside from cosmetic concerns, some females, particularly those with redundant Mons pubis, experience stress urinary incontinence (SUI).
\end{abstract}

Objectives: The aim of current study is to evaluate the procedure of ordinary abdominoplasty with added monsplasty (monspexy) by a simple technique to restore the natural urethral angle, in management of female stress urinary incontinence due to redundant abdomen and Mons pubis besides the aesthetic outcomes.

Patients and Methods: From August 2017 to August 2020, 29 cases of females complaining of redundant abdomen and Mons pubis with some degree of stress urinary incontinence were enrolled in the study. The mean age of patients was 35 years. Intraoperative lower resection level marked at pubic hairline which should about $7 \mathrm{~cm}$ from anterior commissure of vulva and the upper resection limit marked at level of umbilicus.

Results: All surgeries passed smoothly without intraoperative complications with a mean operative time of $194 \pm 30$; range 150-250 minutes and excised tissue weight $4560 \pm 55$; Range 3000-5500 grams. Mean hospital stay was 2.8 \pm 0.7 days with a range of 2-3.5 days, one patient developed hematoma in mons area. As regard stress urinary incontinence the results at 8 weeks postoperative showed significant improvement of Quality of life.

Conclusions: Females who undergo abdominoplasty combined with monspexy in redundant abdomen and Mons pubis benefit from this procedure aesthetically and functionally from added monsplasy which reduces symptoms of stress urinary incontinence.

Key Words: Abdominoplasty - Redundant abdomen - Monspexy - Stress urinary incontinence.

Level of Evidence: Level III - Therapeutic study.

\section{INTRODUCTION}

Abdominoplasty is one of the most popularperformed plastic surgical procedures [1]. Aesthetic abdominoplasty is done to remove excess abdom- inal skin \& fat and improve body contour. In addition to abdominal aesthetic concerns, some females experience stress urinary incontinence (SUI) especiallypostpartum. This problem is well documented and even among women who have only had one child, this may happen. Especially after massive loss of weight [2].

The pubic area as well as the entire lower body should be assessed. Due to the close proximity of the tissues that form an inseparable anatomic structure, its management would be more effective if the surgical strategy took into account the need for a combined approach with the anterior abdominal wall [3].

SUI denotes the involuntary leakage of urine associated with abdominopelvic straining. SUI poorly affectsfemales' quality of life in many ways (e.g., physically, emotionally, and psychologically) [4].

Female stress urinaryincontinence is still an understood subject. SUI may be treated surgically by suspending and supporting the urethra with polypropylene mesh tape or autologous fascia to restore the natural anatomical vesico-urethral angle [5].

Pubic region descent due to skin laxity and fullness due to excess fat, leading to weak supporting muscles and ligaments (peri-urethral, paraurethral ligament, pubo-urethral ligament), so increasing the vesico-urethral angle which becomes straighter makes the urethra sphincter cannot withstand the increased abdominal pressure as during coughing and sneezing, Apart from having a bad cosmetic appearance, pubic functionality may be harmed, resulting in difficulty maintaining hygiene and impaired sexual function. As a result, monspexy 
has become an essential component of body contouring procedures, particularly abdominoplasty $[6,18]$.

The current study's goal is to evaluate the procedure of ordinary abdominoplasty with added monspexy using a simple technique to restore the natural urethrovesical angle, similar to SUI surgical treatments in the management of female stress urinary incontinence due to redundant abdomen and Mons pubis, in addition to the aesthetic outcomes in terms of abdominal contour and patient satisfaction.

\section{PATIENTS AND METHODS}

During the period from August 2017 to August 2020, 29 cases of females complaining of redundant abdomen and Mons pubis and some degree of stress urinary incontinence were enrolled in the study which was conducted in The Surgery Department, Plastic Unit of Benha University Hospital. The mean age of patients was 35 years with a range of 28-44 years. The mean body mass index BMI of patients was $32 \mathrm{~kg} / \mathrm{m}^{2}$ with a range of $28-39 \mathrm{~kg} / \mathrm{m}^{2}$, and the mean parity was 2.5 . The mean age of their children was 5.2 years. Vaginal births accounted for $60 \%$ of all births, while caesarean births accounted for $40 \%$. After an approval from the Research Ethics Committee in Benha Faculty of Medicine and fully informed written consent from all patients regarding surgical procedure, photographing and follow up period, each patient underwent complete history taking and physical examination. Baseline information was recorded (Patients demographic data) Table (1), including age, weight and height. All of the women were evaluated clinically and radiologically, with a particular focus on the impact of a belly abdomen with redundant Mons pubis on their quality of life QOL.

The evaluation of women presenting with symptoms of SUI included questions about the type of incontinence (leakage with stress action, urgency, continuous leakage, or involuntary leakage), patients with a history of pelvic surgeries, particularly hysterectomy, and patients with other risk factors such as smoking (has an irritative effect on the bladder and induces chronic cough). The physical examination included a cough stress test, which included demonstrating urine leakage and visualizing leakage from the urethra with stress maneuvers. The cough stress test is done with a full bladder, about $300 \mathrm{ml}$ measured by ultrasound. The patient is asked to cough and bear down; urine usually comes in small spurts with the cough. Delayed urine loss, particularly large volume loss or complete bladder emptying occurring after coughing, is suggestive of unstable bladder activity (excluded from the study). If the stress incontinence is not demonstrated in the lithotomy position, the test should be repeated in the standing position with the patient's feet comfortably separated at shoulder width. In cases of associated cystocele and/or rectocele, the test is done before and after insertion of a vaginal pack. Cases with a neurogenic bladder or with evident urge incontinence were excluded. Evaluation also included assessment of pelvic organs prolapsed from the vaginal introitus, assessment for urethral hypermobility, post-void residual urine and urine analysis/urine culture to evaluate for the presence of hematuria and/or infection to exclude other causes of stress urinary incontinence. Routine laboratory and radiological studies were performed on all patients, including pelviabdominal ultrasound and voiding urethrogram for assessment of vesico-urethral angle to evaluate redundant Mons pubis induced stress urinary incontinence, as well as urodynamic studies to rule out other causes of stress urinary incontinence.o The following studies were done: Preoperatively. The system used in urodynamic evaluation was Delphis, KT Labories Company, Germany.

- Uroflowmetry.

- Cystometry.

- ALPP (abdominal leak point pressure).

- Pressure-flow study.

All done to exclude other types of urinary incontinence and to assure that this is stress urinary incontinence caused by redundancy of urethral and periurethral tissues due to redundant lower abdomen and Mons pubis.

\section{Technique:}

Mons measurements: Invertedisosceles triangle.

- Umbilicus to symphsis pubis $=17 \mathrm{~cm}$.

- Pubic hairline to upper end of labia majora $=6$ $8 \mathrm{~cm}$.

- Length of labia majora $=5-7 \mathrm{~cm}$.

- Lengths of side segment lines. (Upper end of labia majora along the inguinal crease up to lateral hairline) $=13 \mathrm{~cm}$.

- Lengths of base of mons triangle $=16 \mathrm{~cm}$.

- Inguinal crease/pubic hairline angle (corner of mons triangle) $55=$ degrees.

- Inguinal crease to the upper labia majora angle (tip of mons triangle $)=70$ degrees [7]

Pre-operative marking with the patient in a standing position included the midline and about 
$5 \mathrm{~cm}$ besides the midline bilaterally for midline tunnel dissection. Resection level is marked at the pubic hairline, which should be about $7 \mathrm{~cm}$ from the anterior commissure of the vulva and the upper resection limit is marked at the level of the umbilicus. In terms of monsplasty, we asked the patient to pull the abdominal pannus upwards to maximally stretch the Mons pubis, and we marked this level to be taken into account during the operation for Mons fixation. All patients received spinal anesthesia with sedation. After sterilization, draping, and tumescent solution infiltration $(1000 \mathrm{ml}$ Ringer's lactate + adrenaline $1 \mathrm{mg}+25 \mathrm{ml}$ lidocaine $2 \%$ ), we began with a lower incision to spare Scarpa's fascia in midline above Mons pubis for its fixation and bilaterally to preserve sub Scarpa's lymphatic and vascular plexuses to reduce the rate of seroma formation and vascularity of abdominal flaps. Dissection continued to the level of the umbilicus, which was preserved for translocation to its new position in the upper flap, after which dissection was restricted in the midline tunnel marked previously, and upper incision made after approximation to the lower flap without tension. In the monspexy technique, a restricted deep dissection of the Monspubis fascia in the midline region downwards to the pubic bone was used. Then, after good hemostasis, the head of the table was tilted up to 45 degrees for tension-free closure in three layers: Fascia, deep dermal, and skin over two subcutaneous drains, after translocation of the umbilicus to its new position in the upper flap, and an abdominal binder was applied.

Patient followed-up in post-operative period for viability of flaps and umbilicus and removal of drains when contents became less than $30 \mathrm{ml}$ per day.

Evaluation of patients post-operatively. For any procedure-related complications such as flap necrosis, umbilical necrosis, wound infection, prolonged seroma formation, and bleeding. Then, after edema subsided, we evaluate patients for satisfaction subjectively by satisfaction scores. We use the Likert scale before and after the procedure, comparing between contours, irregularities, scars, symmetry and objectively by comparing preoperative and post-operative photos by other physicians not included in the procedure. In terms of stress urinary incontinence, patients' subjective improvement and objective evaluation of obtaining vesico-urethral angle after Mons-pubis fixation upwards were used.

International Consultation on Incontinence Questionnaire-Urinary Incontinence-Short Form.
This is a multiple choice questionnaire asking the patient to score the frequency of urine leakage; how much she leaks; and, on a scale of 1 to 10 , how much it interferes with daily life. The maximum score is 21 with urine leaking all the time. Patients completed the questionnaires before the procedure and at 8 weeks post-operatively [8].

\section{Statistical analysis:}

The obtained data were expressed as means $\pm \mathrm{SD}$, ranges, numbers and percentages. Statistical analysis was conducted using One-way Analysis of Variance (ANOVA test) or Wilcoxon Ranked Test for Unrelated Data (Z test). Possible correlations were conducted using Pearson's correlation coefficient. Statistical analysis was performed using the SPSS program (Version 10, 2002) and the $p$-value was considered significant if less than 0.05 .

\section{RESULTS}

The study included 29 females with redundant abdomen and Mons-pubis and some degree of stress urinary incontinence. The mean age was $37 \pm 5.5$ with a range of $29-47$ years. There were 17 obese females and 17 overweight females, with a mean body mass index (BMI) of $30.62 .2 \mathrm{~kg} / \mathrm{m}^{2}$ ranging from 27.3 to $34.9 \mathrm{~kg} / \mathrm{m}^{2} .5$ patients were diabetic, 5 patients were hypertensive and $23 \mathrm{fe}$ males were free of co-morbidity. All of the females who enrolled were multipara. Details of enrollment data are shown in Table (1).

All surgeries passed smoothly without intraoperative complications with a mean operative time of 194 \pm 31.3 minutes; Range 150-250 minutes and excised tissue weight of $4560 \pm 1200$ grams; Range 3000-5500 grams. Immediate postoperative care consisted of proper analgesia, antibiotic therapy and intravenous fluids with care in a semi-setting position. When patients were well oriented and anesthesia passed, oral fluids and ambulation were allowed. The mean hospital stay was $2.8 \pm 0.7$ days with a range of 2-3.5 days. Table (2).

All patients passed a smooth postoperative course but 2 patients (6.9\%) developed prolonged seroma formation for about 11 days but all other patients' drains were removed after about $7 \pm 2$. One patient developed hematoma in the Mons area, which was conservatively treated, and two patients developed partial wound dehiscence, which was also conservatively treated without revision surgery. After 8 weeks, 5 patients developed hypertrophied scars which were treated with steroid injection and silicone sheet application. Table (3). 
Abdominal measurements were re-estimated at 8 weeks after surgery while the patient was in lying and standing positions. Post-operative estimates revealed a significant difference in abdominal contour, Mons pubis contour, as well as the location and shape of the umbilicus, when compared to preoperative measurements. Table (4).

Final results of patient's satisfaction are summarized in Table (5) and Fig. (1) by using the Likert scale comparing preoperative status with post-operative status showed a significant difference regarding the aesthetic outcome ( $p$-value $<0.05$ ), with an overall upper percent of the very satisfied patients in comparison with the preoperative condition.

At 8 weeks after surgery, all patients were satisfied by their surgical outcome with a mean score of satisfaction rate of $8.1 \pm 1.1$; with a range of 7-9. The average patient satisfaction rate for abdominal and mons contour was 7.4-1.1, with a range of 6-9. Table (5).

As regard stress urinary incontinence at 8 weeks after surgery the history of patients during this period showed significant improvement of Quality of life due to improving this symptom and for objective assessment voiding urethrogram was done showing improvement of vesico-urethral angle (preserved angle instead of straight angle preoperative). Table (6) \& Figs. $(2,12)$.

Evaluations of success of treatment and quality of life were based on history-taking and objective patient evaluation according to the International Consultation on Incontinence Questionnaire - Short Form (ICIQ-SF). The ICIQ-SF score dropped from $14.2( \pm 3.9)$ to $6.75( \pm 5.9)$ but with no significant difference ( $p$-value 0.54 ) (Tables 7,8).

Table (1): Patients enrollment (demographic) data.

\begin{tabular}{lll}
\hline Data & & Finding \\
\hline Age (years) & <30 years & $2(6.9 \%)$ \\
& 30-40 years & $17(28.6 \%)$ \\
& $>40$ years & $10(34.5 \%)$ \\
& Total & $37.8 \pm 5.5(29-47)$ \\
Body weight $(\mathrm{kg})$ & & $80.8 \pm 9.5(75-97)$ \\
Body height $(\mathrm{cm})$ & & $192.4 \pm 3.8(157-168)$ \\
BMI $\left(\mathrm{Kg} / \mathrm{m}^{2}\right)$ & Overweight & $17(58.6 \%)$ \\
& $<(25-30)$ & $12(41.4 \%)$ \\
& Obese(30-35) & $30.6 \pm 2.2(27.3-34.9)$ \\
Total & $5(17.2 \%)$ \\
Co-morbidities & Type-2 DM & $5(10.4 \%)$ \\
& Hypertension & $21(72.4 \%)$ \\
& No &
\end{tabular}

- Data are presented as mean \pm SD \& numbers, ranges and percentages are in parenthesis.
Table (2): Operative and post-operative data.

\begin{tabular}{lll}
\hline Data & \multicolumn{1}{c}{ Finding } \\
\hline Operative time (min) & & $194 \pm 31.4(150-250)$ \\
Weight of excised & & $4560 \pm 1200(3000-5500)$ \\
tissue (gm.) & 2 days & $9(34.5 \%)$ \\
Hospital stay (days) & 3 days & $15(51.7 \%)$ \\
& 4 days & $4(13.8 \%)$ \\
\hline & Total & $2.8 \pm 0.7$ (range 2-3.5) \\
\hline
\end{tabular}

- Data are presented as mean \pm SD \& numbers, ranges and percentages are in parenthesis.

Table (3): Complications.

\begin{tabular}{cl}
\hline Data & Finding \\
\hline Prolonged seroma & $2(6.9 \%)$ \\
Minor dehiscence & $2(6.9 \%)$ \\
Mons hematoma & $1(3.4 \%)$ \\
Scar hypertrophy & $5(17.2 \%)$ \\
\hline
\end{tabular}

Table (4): Abdominal and Mons measurements.

\begin{tabular}{lll}
\hline Data & & \multicolumn{1}{c}{ Finding } \\
\hline Xiphisternum to & Preoperative & $24.9 \pm 3(20-27)$ \\
umbilicus & Postoperative & $17.2 \pm 2(17-19)$ \\
& Statistical difference & $\mathrm{Z}=4.510, p<0.001$ \\
Umbilicus to & Preoperative & $21.4 \pm 2(20-25)$ \\
hairline & Postoperative & $17 \pm 3(17-20)$ \\
& Statistical difference & $\mathrm{Z}=4.707, p<0.001$ \\
Hairline to labia & Preoperative & $10.3 \pm 2(10-14)$ \\
majora & Postoperative & $7.3 \pm 1(7-10)$ \\
& Statistical difference & $\mathrm{Z}=4.720, p<0.001$ \\
\hline
\end{tabular}

- Data are presented as mean \pm SD \& numbers, ranges and percentages are in parenthesis.

Table (5): Likert scale of patient satisfaction.

\begin{tabular}{llllll}
\hline Likert scale & $\begin{array}{c}\text { Very } \\
\text { satisfied }\end{array}$ & Satisfied & Unsatisfied & $\begin{array}{c}\text { Very } \\
\text { unsatisfied }\end{array}$ & $\begin{array}{c}p- \\
\text { value* }\end{array}$ \\
\hline Shape & $(40 \%)$ & $(33.33 \%)$ & $(20 \%)$ & $(6.67 \%)$ & 0.014 \\
Irregularities & $(46.67 \%)$ & $(33.33 \%)$ & $(13.33 \%)$ & $(6.67 \%)$ & 0.028 \\
Scars & $(26.67 \%)$ & $(53.33 \%)$ & $(13.33 \%)$ & $(6.67 \%)$ & 0.019 \\
Symmetry & $(40 \%)$ & $(40 \%)$ & $(20 \%)$ & 0 & 0.011 \\
\hline
\end{tabular}

- Data are presented as mean \pm SD \& numbers, ranges and percentages are in parenthesis.

Table (6): Improvement in stress urinary incontinence.

\begin{tabular}{lcccc}
\hline & $\begin{array}{c}\text { Preoperative } \\
\text { number of } \\
\text { cases }\end{array}$ & $\begin{array}{c}\text { Postoperative } \\
8 \text { weeks } \\
\text { number } \\
\text { of cases }\end{array}$ & $\begin{array}{l}\text { Improved } \\
\text { patients }\end{array}$ & $\begin{array}{l}\text { Statistical } \\
\text { difference }\end{array}$ \\
\hline $\begin{array}{l}\text { Subjectively by } \\
\text { symptoms }\end{array}$ & $29(100 \%)$ & $6(20.7 \%)$ & $23(79 \%)$ & $p<0.001$ \\
$\begin{array}{l}\text { Objectively by } \\
\text { clinical cough } \\
\text { stress test }\end{array}$ & $24(82.7 \%)$ & $4(13.8 \%)$ & $20(68 \%)$ & $p<0.001$ \\
$\begin{array}{l}\text { urethral and } \\
\text { radiological } \\
\text { by angle }\end{array}$ & & & & \\
abnormality & & & & \\
\hline
\end{tabular}


Table (7): International Consultation on Incontinence Questionnaire Short Form (ICIQ-SF).

\begin{tabular}{clll}
\hline $\begin{array}{c}\text { How many } \\
\text { Question } \\
\text { times do you } \\
\text { leak urine? }\end{array}$ & $\begin{array}{c}\text { How much } \\
\text { urine do } \\
\text { you leak? }\end{array}$ & $\begin{array}{c}\text { How much } \\
\text { urine leaks } \\
\text { interfere with your } \\
\text { daily lifetimes? }\end{array}$ \\
\hline Response & 0- Never & 0- None & 0 (not at all) \\
1- About once & 2-A small amount & 1 \\
a week or less & 4- A moderate & 2 \\
often & amount & 3 \\
2- Two or three & 6- A large amount & 4 \\
times a week & & 5 \\
3- About once & & 6 \\
a day & & 7 \\
4- Several times & & 8 \\
a day & & 9 \\
5- All the time & & 10 (a great deal) \\
\end{tabular}

Table (8): Results of ICIQ-SF.

\begin{tabular}{lccc}
\hline Scale & Pre-operative & Post-operative & $p$-value \\
\hline ICIQ-SF (mean/SD) & $14.2( \pm 3.9)$ & $6.75( \pm 5.9)$ & 0.54 \\
\hline
\end{tabular}

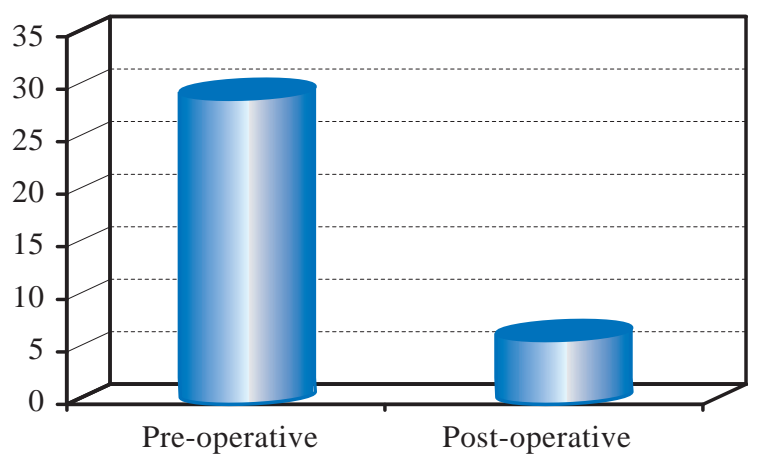

Subjectively
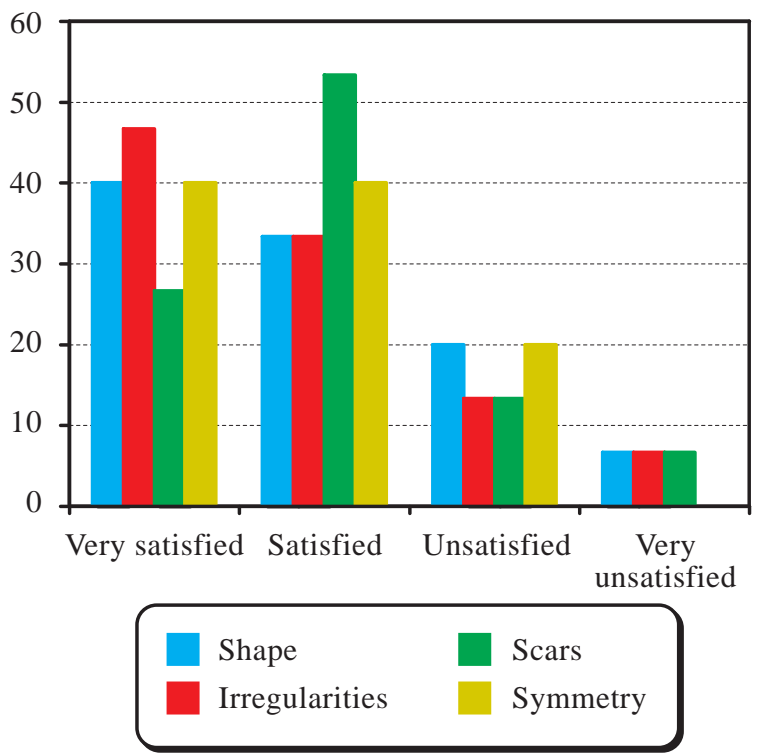

Fig. (1): Diagram showing results of Likert scale of patient satisfaction.

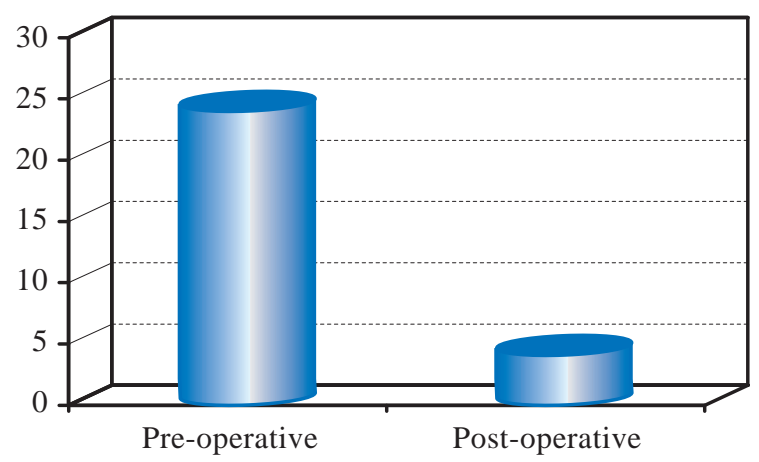

Objectively

Fig. (2): Improvement in stress urinary incontinence.
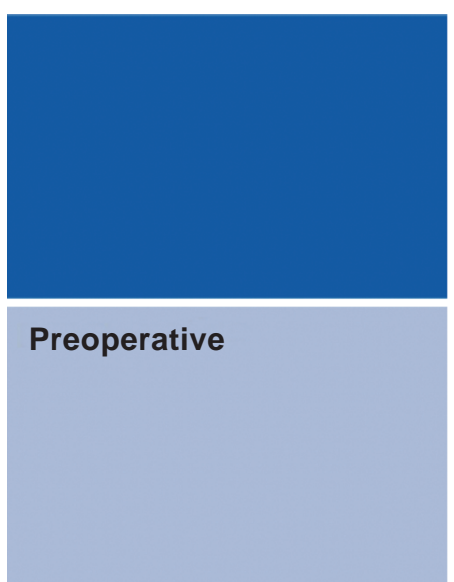

\section{Suggested postoperative}
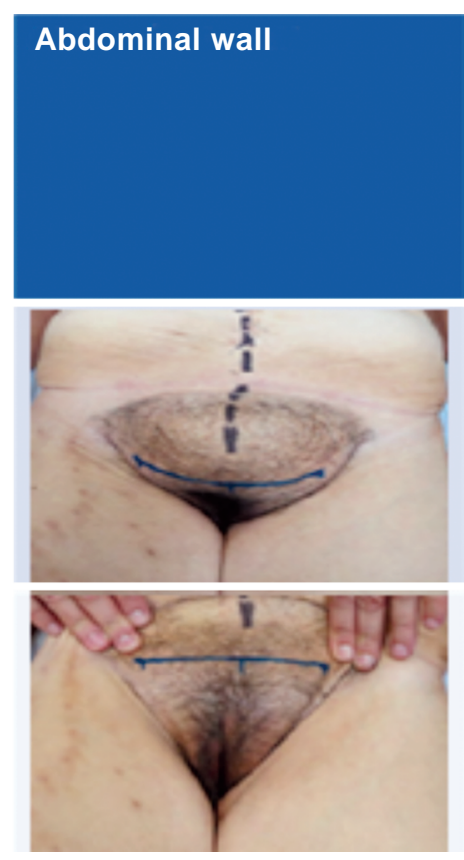
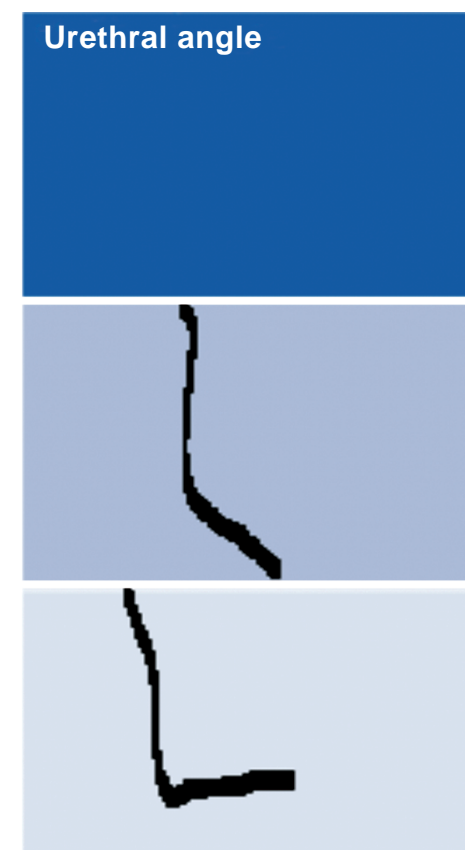

Fig. (3): Show predicted improvement of urethral angle after stretching mons fascia upwards by diagram. 

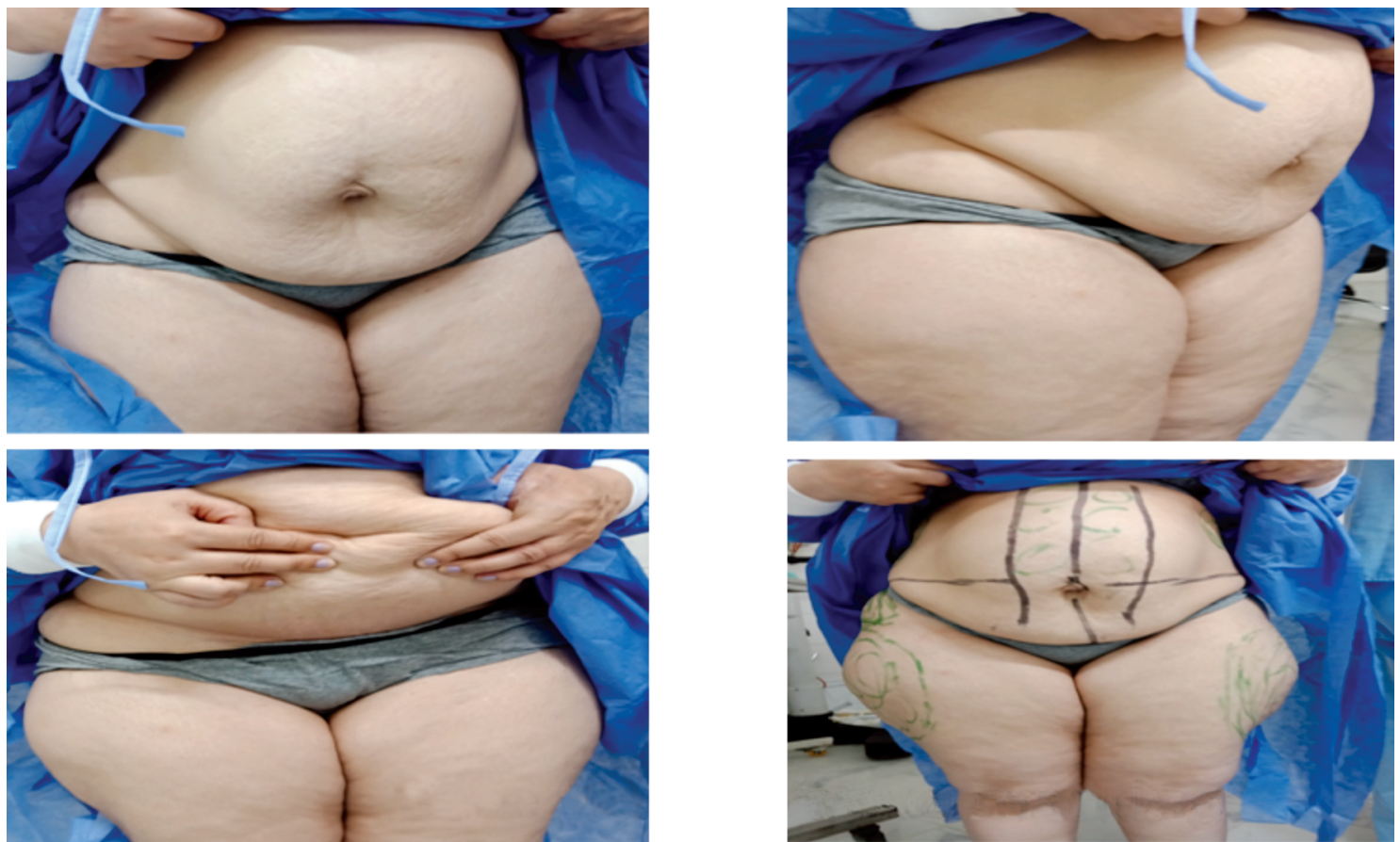

Case (1): Pre-operative marking.

Fig. (4): Show pre-operative photo frontal and side views and pre-operative marking of upper.
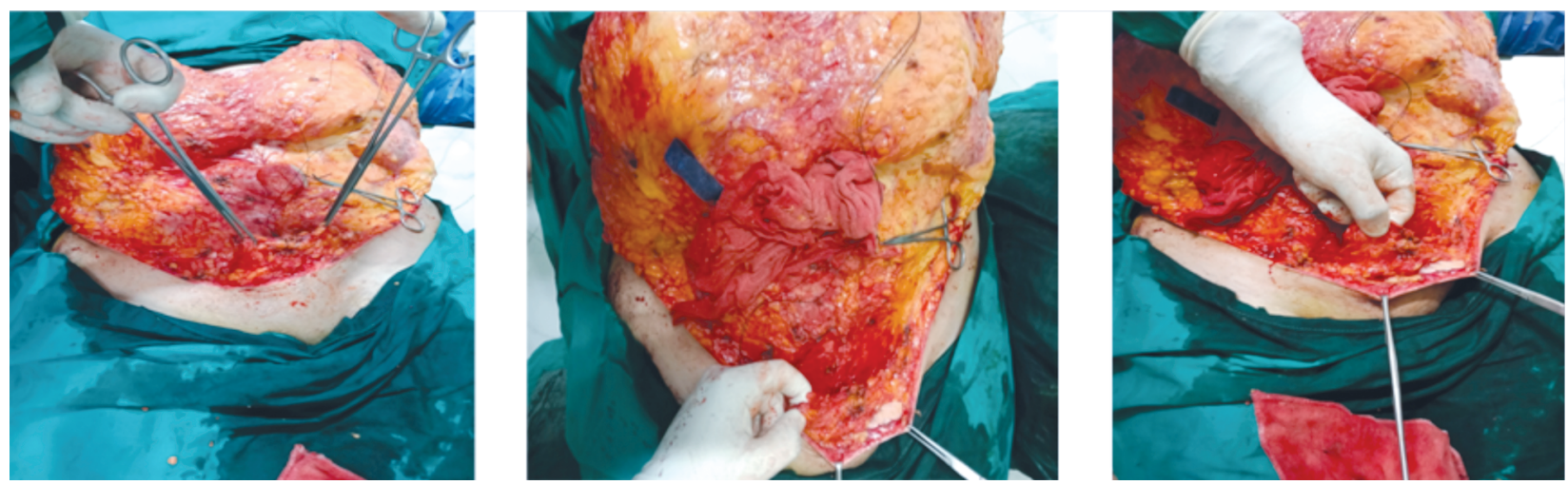

Case (1): Intraoperative marking showing monspubis scarpa's fascia.

Fig. (5)

Case (1): Post-operative early view.

Fig. (6)

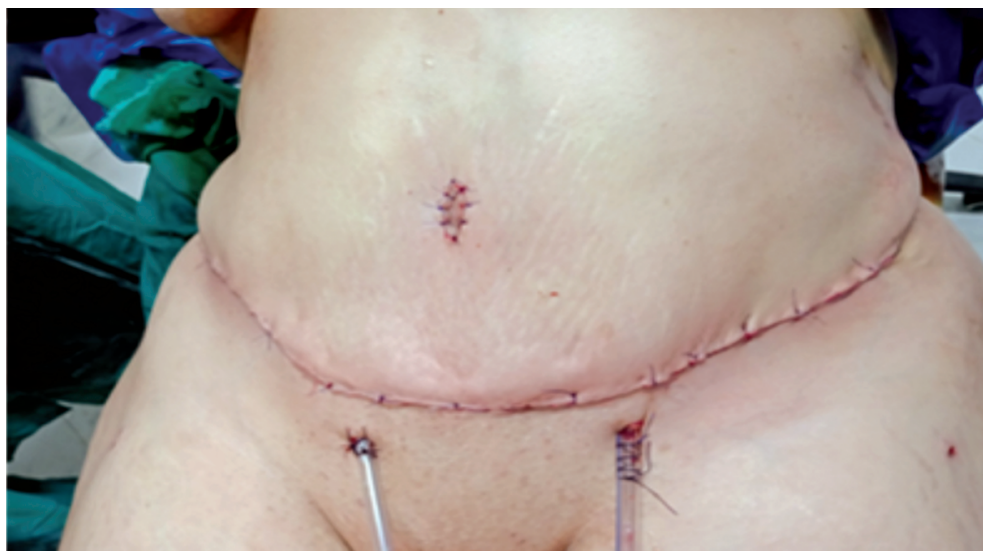



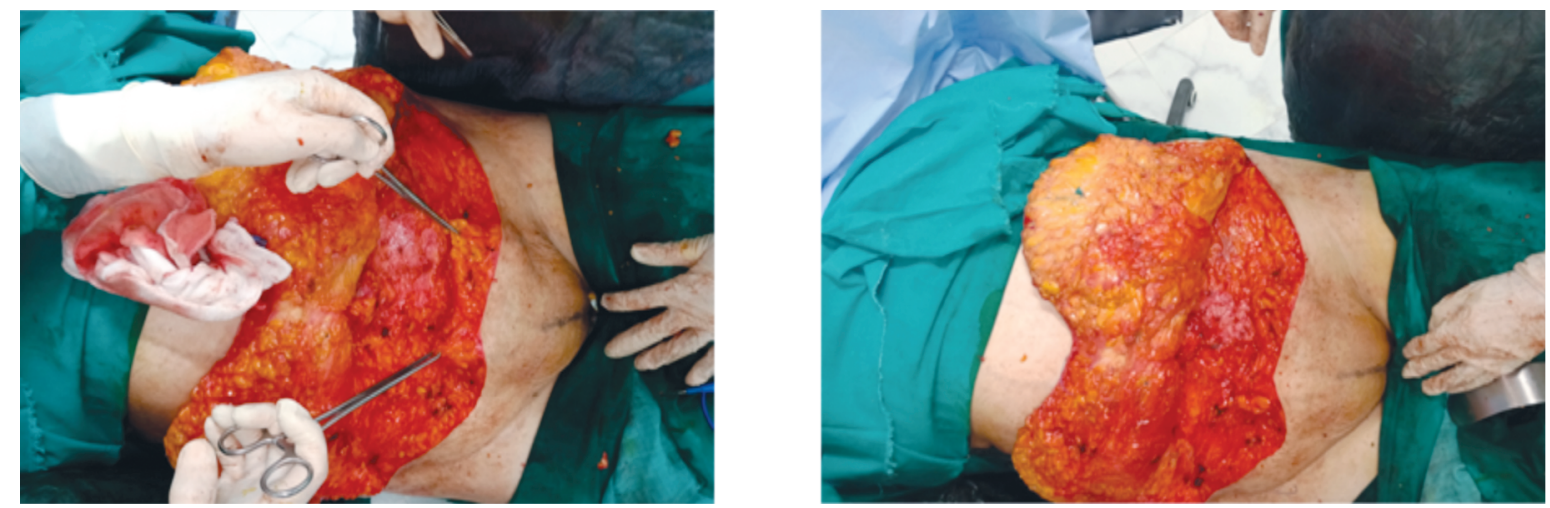

Case (2): Intraoperative marking showing monspubis scarpa's fascia and before \& after fixation.

Fig. (7)
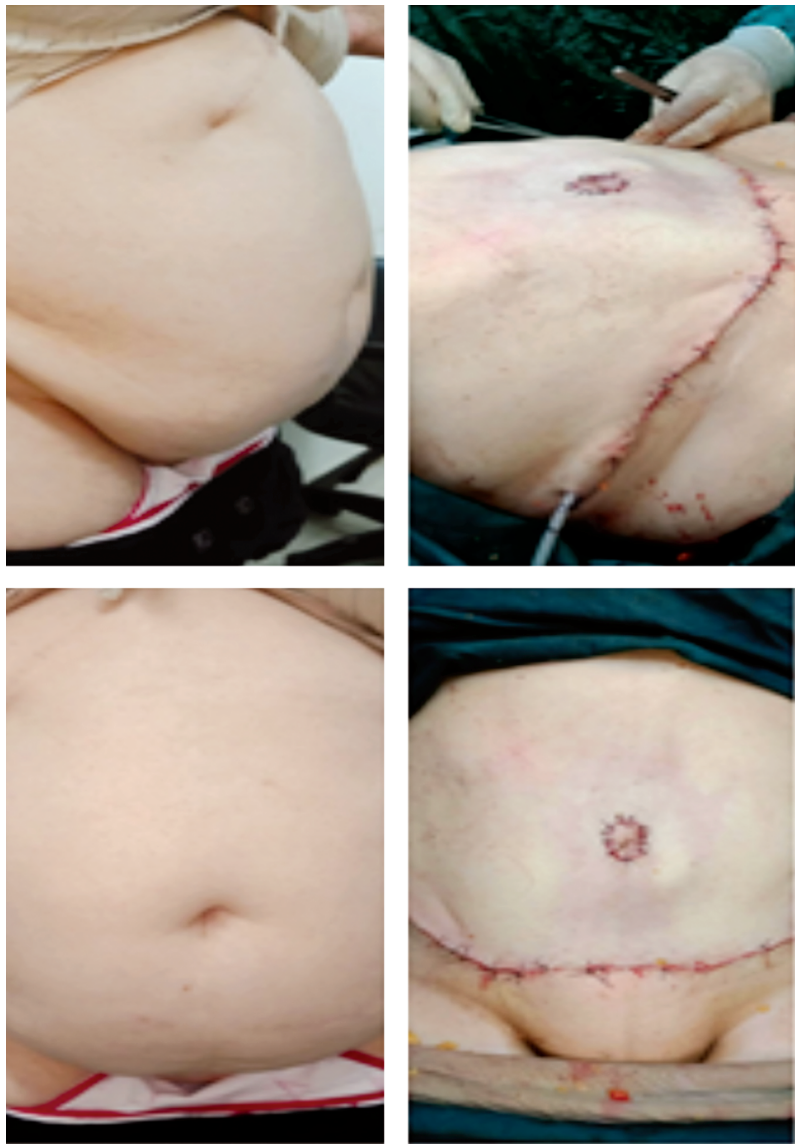

Fig. (8): Pre and post-operative views.

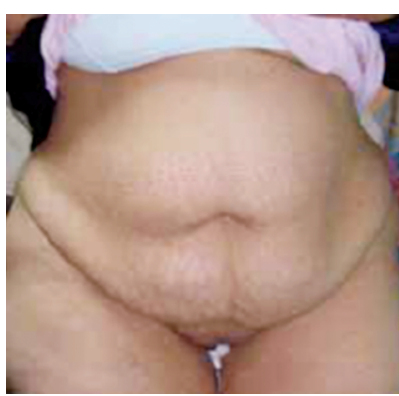

Pre-operative

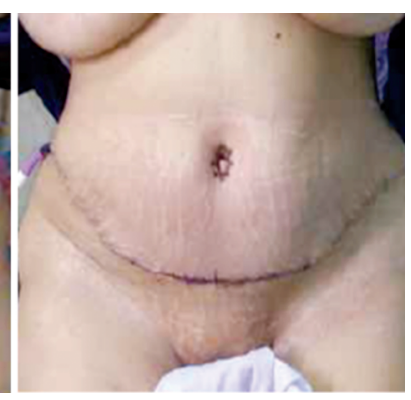

Post-operative
Fig. (9)

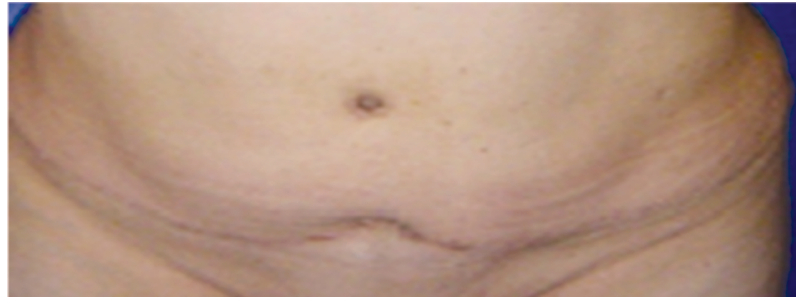

Fig. (10): Limited wound dehiscence.
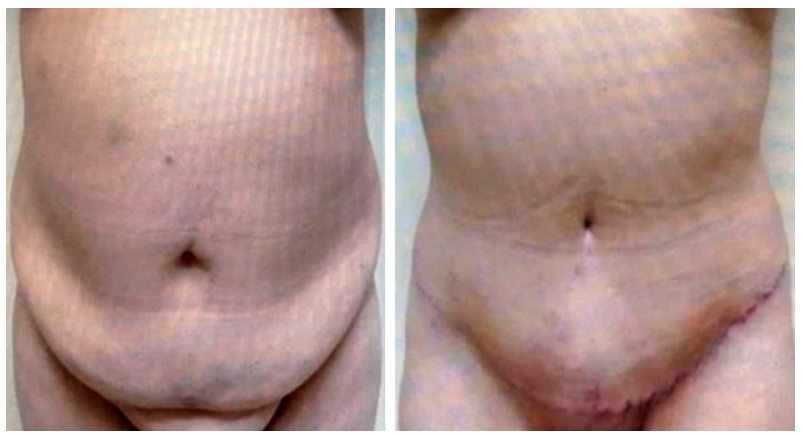

Fig. (11): Pre-operative and early post-operative.

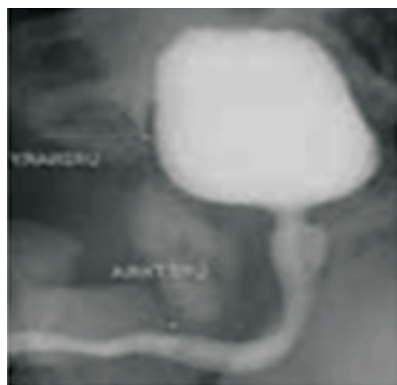

Pre-operative

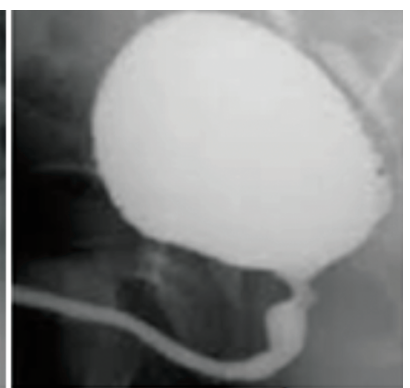

Post-operative
Fig. (12): Voiding urethrogram before and after monspexy (note the urethrovesical angle).

\section{DISCUSSION}

Papadopoulos et al., have shown in previous studies that in addition to aesthetic improvements, many females who have undergone abdominoplasty report functional benefits post-operatively, such 
as better mobility, independence and improved quality of life, However, patients do not typically mention SUI symptoms during pre-operative consultation for abdominoplasty, nor do they consider this surgery as a means to improve SUI. SUI denotes the involuntary leakage of urine associated with abdominopelvic straining. SUI has a negative impact on females' quality of life in many ways (physically, emotionally, psychologically, and economically), but in this study we discussed both aesthetic and functional (SUI) disorders and added a step called monspexy [4].

Few studies have demonstrated the relationship between abdominoplasty and SUI Smith et al., first suggested an association between abdominoplasty and relief of stress urinary incontinence in 1998. They evaluated 12 young men who had congenital prune-bellysyndrome (a triad of cardinal features that includes undescended testes, urinary tract dilatation and laxity of the abdominal wall musculature). These authors reported that 7 of 8 patients with preoperative SUI improved after Monfortabdominoplasty [9].

Kristen M. and Loren J describe a technique for Mons pubis reduction in width through medial thigh lifting incision which was jeopardized by several complications such as disturbance of lymphatic of the lower limb [10].

Another surgeon, Kevin J, describes liposuction of the Mons pubis as a tedious maneuver that requires deep liposuction while preserving lymphatic, otherwise it will result in non-resolving lymphedema with recurrent lymphangitis that may spread to the labia in females, but in our study, the deep dissection level to the Scarpa's fascia spared Mons pubis lymphatic that drain into the inguinal artery [11].

Guneren E, et al., in a study of abdominoplasty with concomitant SUI, anecdotal data of improvement in SUI following abdominoplasty revealed that the patient's relief of symptoms was attributed to midline plication, a "very low incision," and bulk reduction of the lower abdominal wall [12]. In a wide study to date, Solanki et al approached 100 abdominoplasty patients to request their participation in a retrospective survey. 27 (58.7\%) of their 46 respondents had SUI preoperatively, and 7 (25.9\%) of these 27 patients following surgery noticed an improvement in their symptoms. However, in our study, 23 (79\%) of 29 patients improved symptomatically, which was significant. This may be due to the addition of the step of monspexy, which elevates the Mons while maintaining a satisfactory vesico-urethral angle [5].

The abdominal deep layer of the superficial fascia system (also known as Scarpa's fascia) is membranous and continuous with the superficial perineal fascia (Colle's fascia) of the urogenital triangle. Just below Colle's fascia is the deep perineal fascia (Gallaudet's fascia), which covers the perineal membrane and the superficial perineal space muscles (ischiocavernosus and bulbospongiosus) [13]. And this may explain the anatomical findings in our study, as elevation of Scarpa's fascia and fixing it in abdominal aponeurosis well elevate and fix perineal superficial and deep fasciae (enclosing perineal muscles and urogenital systems). Peri-urethral ligaments and muscles besides normalization of the vesico-urethral angle and the urethra becomes less mobile and the tight abdominal closure reflecting the increased pressure on both anterior and posterior urethral walls helps its collapse during coughing or sneezing.

The study by Green TH revealed that Mons pubis and fascia enclosing the urethra are placed under tension even with mild soft-tissue resection, and the resulting midline tissue gap is strengthened by a layered closure from fascia to skin. Because Scarpa's fascia is continuous with Colle's fascia of the urogenital triangle, which contains the urogenital diaphragm and the external urethral sphincter, tight closure of this fascia could improve involuntary micturition. Given these potential anatomic chasms, this tension could lengthen the urethra and offset the shortening and opening action of its intrinsic smooth muscle during normal micturition [14].

The mechanism of improvement in urinary symptoms is the subject of several theories. In some studies by Güneren et al., revealed that the improvement was due to reduction in the anterior abdominal wallbulk. Also Mast BA revealed that increased strength of the anteriorabdominal wall by positioning the rectus muscles at the midline leading to more complete bladder emptying. Carruthers et al., revealed that tensioning of the Mons pubis and Scarpa's fascia, which is contiguous with Colle's fascia of the urogenital triangle, acts to lengthen the urethra and improve continence. There is a consensus recently that pubovaginal sling tape and retropubic urethropexy are satisfactory techniques to manage stress urinary incontinence offering the best continence results after long term follow-up [19], so it is a matter of fixation of the urethra upward and this what was done fixation of scarpa fascia which continuous with the fascia 
enclosing urethra upward in the abdominal aponeurosis in redundant abdomen which was consider the cause of laxity and SUIdevelopment.

Finally Myers TW et al., revealed this concept of tension distributed throughout the fascial network to effect change at a distant point is central to the tensegrity theory of biomechanics $[\mathbf{1 2 , 1 5 , 1 6 , 1 7 ]}$.

\section{Conclusions:}

Patients who undergo an abdominoplasty with monspexy in the redundant abdomen and Mons pubis get a lot out of the operation, both aesthetically and functionally, since the monspexy decreases symptoms of stress urinary incontinence. Anatomic studies are needed to evaluate the exact surgical maneuver that can enhance continence during abdominoplasty and to classify the patients with SUI who are most likely to benefit from this procedure.

\section{Ethics approval:}

All procedures performed in the study involving human participants were in accordance with the ethical standards of our institutional research committee.

\section{Declaration of patient consent:}

The authors certify that they have obtained all appropriate patient consent forms, the patients signed informed consent regarding publishing their data and photographs in the journal.

\section{Financial support and sponsorship:}

None.

\section{Conflicts of interest:}

Ayman M. Abdelmofeed, Ola Seif, Mohamed T. Younes, Shabieb A. Abdelbaki declare that they have no conflict of interest.

\section{REFERENCES}

1- Richter D.F. and Stoff A.: Abdominoplasty procedures. In: Nelligan PC, ed. Plastic Surgery. Vol. 2. $3^{\text {rd }}$ ed. Philadelphia, Pa.: Elsevier Saunders, 529-558, 2013.

2- Liang C.C.,Wu M.P., Lin S.J., et al.: Clinical impact of urinary incontinence in women 5 years after first delivery. Int. Urogynecol. J., 24 (1): 99-104, 2012.

3- Flavio Henrique Mendes 1,2, Fausto Viterbo 2, José Marcos Gabas 2 and Rafael José De Castro: Revisiting Post bariatric Monsplasty Rev. Bras. Cir. Plást., 32 (3): 383-390, 2017.

4- Papadopoulos N.A., Staffler, Mirceva V., et al.: Does abdominoplasty have a positive effect on quality of life and emotional stability? Plast. Reconstr. Surg., 129 (6): 957e-962e, 2012.

5- Solanki N.S., Duffield J.A., Dean N.R. and Morgan R.G.: The effect of abdominoplasty on urinary incontinence in women. Plast. Reconstr. Surg., 126 (4): 206e-209e, 2010.

6- Rubin P. and Gusenoff J.: Bodylifts and post massive weight loss body contouring. In: Chung K.C., Disa J.J., Gosain A.K., Kinney B., Rubin J.P., eds. Plastic Surgery: Indications and Practice. Philadelphia, PA: Saunders, 1627-1664, 2008.

7- Matarasso A. and Wallach S.: Abdominal contouring surgery: Treating all aesthetic units, including the mons. Aesthetic J. Surg., 21: 111-119, 2001.

8- Timmermans L., Falez F., Mélot C. and Wespes E.: Validation of the use of International Consultation on Incontinence Questionnaire Urinary Incontinence Short Form (ICIQUI- SF) for impairment rating: A transversal retrospective study of 120 patients. Neurourol. Urodyn, 32: 974-979, 2013.

9- Smith C.A., Smith E.A., Parrott T.S., et al.: Voiding functions in patients with prune-belly syndrome after Monfort abdominoplasty. J. Urol., 159: 1675-1679, 1998.

10- Kristen M. and Loren: Integration of the Vertical Medial Thigh Lift and Monsplasty: The Double-Triangle Technique. Plast. Reconstr. Surg., 126 (3): 153e-154e, 2010.

11- Kevin J.: Technical Considerations Regarding Liposuction of the Mons Pubis. The American Journal of Cosmetic Surgery, Vol, 29, No. 1: 72-75, 2012.

12- Guneren E., Eroglu L., Kocak I., et al.: Urinary incontinence was improved after abdominoplasty using a very low incision. Plast. Reconstr. Surg., 104 (5): 1582-1584, 1999.

13- Herschorn S.: Female pelvic floor anatomy: The pelvic floor, supporting structures, and pelvic organs. Rev. Urol., 6 (Suppl 5): S2-S10, 2004.

14- Green T.H.: Classification of stress urinary incontinence in the female: An appraisal of its current status. Obstetric Gynecology Survey, 23: 632-634, 1968.

15- Mast B.A.: Alleviation of urinary incontinence after abdominoplasty. Ann. Plast. Surg., 42: 456-457, 1999.

16- Carruthers K.H., Kocak E., Hulsen J.H. and McMahan J.D.: Improvement in stress urinary incontinence after abdominoplasty. Aesthet. Surg. J., 34: 1091-1098, 2014.

17- Myers T.W.: Anatomy Trains: Myofascial Meridians for Manual and Movement Therapists. $2^{\text {nd }}$ ed. New York: Churchill Livingstone, 2009.

18- Kim J.K., Kim Y.J., Choo M.S. and Cho K.S.: The urethra and its supporting structures in women with stress urinary incontinence: MR imaging using an endo-vaginal coil. AJR Am. J. Roentgenol., 180: 1037-1044, 2003.

19- Norris J.P., Breslin D.S. and Staskin D.R.: Use of synthetic material in sling surgery: A minimally invasive approach. J. Endourol., 10: 227-30, 1996. 